\title{
Da teoria à prática: a dança como uma ferramenta semiótica de tradução
}

Carlos Gonçalves Tavares*

\begin{abstract}
RESUMO: O presente estudo tem por objetivo relacionar conceitos da semiótica de Charles Sanders Peirce e da tradução intersemiótica nas criações em dança, a partir dos diálogos entre dança e literatura e outras linguagens artísticas, como o teatro e aparatos técnicos. A literatura possui ligação intima com o balé clássico, através dos libretos do século XVIII. Os libretos eram utilizados como um roteiro narrativo da obra literária em que se adaptavam os espetáculos de balé, como "O Quebra-Nozes" e "A bela Adormecida". Na dança contemporânea notamos a tradução de características estéticas literárias em coreografias, como o espetáculo May $B$, criado por Maguy Marin e inspirado no universo estético do dramaturgo Samuel Beckett.
\end{abstract}

PALAVRAS-CHAVE: tradução intersemiótica. dança. história da dança

ABSTRACT: This study aims to relate concepts of Semiotics of Charles Sanders Peirce and Intersemiotic Translation, in creations in dance, from the dialogue between dance and literature and other art forms such as theater and technical devices. The literature has intimate connection with classical ballet through the librettos of the eighteenth century. The librettos were used as a narrative script of literary work in which they adapted the ballet performances such as "The Nutcracker" and "Sleeping Beauty". In contemporary dance noticed the translation of literary aesthetic features in choreography as the show May B, created by Maguy Marin and inspired by the aesthetic universe of playwright Samuel Beckett.

KEYWORDS: intersemiotic translation. dance. dance history

\footnotetext{
*Carlos Gonçalves Tavares é Mestre em Comunicação pela Universidade Federal de Juiz de Fora (MG), licenciado em Educação Física pelas Faculdades Sudamérica (Cataguases-MG) e possui experiência como ator e bailarino em dança contemporânea. Atualmente é bailarino e artista pesquisador no Projeto Girarte (MG).
} 
É inegável a capacidade da dança de traduzir, recriar e contextualizar situações, questões e obras de outras áreas em suas criações. Isso remonta os primórdios da humanidade. As danças tribais, realizadas para agradecer aos deuses e pedir proteção, pode-se dizer que se trata de uma espécie de tradução da oração verbal em movimentos que exaltam e glorificam o divino, o espiritual. O balé clássico, oriundo da corte francesa, tem como principal característica transcrever histórias em coreografias, como os balés de repertório, $O$ lago dos cisnes, $O$ quebra-nozes e Giselle, importantes pela sua excelência artística e impecabilidade na tradução de história em movimento.

A dança por se tratar de uma área das artes cênicas, emprega o uso de outros elementos e linguagens artísticas, como o teatro, o cenário e a iluminação, contribuindo para a concepção da obra. Uma característica importante é a relação da dança com outras linguagens artísticas, sendo uma delas a literatura. Na história do balé clássico observamos que a adaptação ou tradução da literatura para coreografias é um fato comum.

Segundo Aguiar e Queiroz (2008, p. 8):

As coreografias eram habitualmente elaboradas a partir de libretos, escritos por libretistas ou autores de partitura musicais para os balés. Os libretos consistiam no guia de narrativa da obra. As histórias eram desenvolvidas por diferentes autores, e depois "traduzidas" ou adaptadas, pelos coreógrafos. Frequentemente os libretos eram traduções de obras literárias bastante conhecidas.

No Balé Clássico, as narrativas e ambientes ilusórios são os eixos condutores da obra. Devido às transformações sociais da idade moderna, percebeu-se determinados modos presentes no balé e o mesmo passou a ser questionado. Assim, variadas vertentes da chamada dança moderna começaram a surgir. É importante notar que, nesta época, o contexto social determinava fortemente as realizações artísticas, fazendo com que a dança moderna se tornasse bastante diferente da dança expressionista, movimento europeu, mesmo que tendo alguns elementos em comum.

Alexandorvich Vsevolozhsky, diretor e libretista dos Teatros Imperiais Russos, teve papel importante para a criação do balé "A bela adormecida", de 1890. O libreto deste balé, criado por Marius Petipa, tinha modificações em relação ao conto de Jules Perrault, criando algumas cenas e omitindo outras. Outro exemplo de traduções para o balé realizado por Petipa em 
colaboração com Vsevolozhsky foi "O quebra nozes", de 1892. A coreografia partiu de um libreto que traduz o original de Ernst Theodro Amadeus Hoffmann com música de Tchaikovsky, composta para o balé (CANTON, 1994).

Para Mallarmé, o autor do libreto e o compositor continuavam a ser os criadores do balé, sendo o coreógrafo apenas alguém encarregado de dar corpo às suas sugestões (SASPORTES, 2003).

Sobre a tradução intersemiótica, o linguista Roman Jakobson (1959) dizia que a mesma pode ser definida como transmutação de signos, de um sistema semiótico para outro sistema, de outra natureza.

O autor completa o pensamento dizendo que tradução intersemiótica ou "transmutação", consiste na interpretação dos signos verbais por meio de sistemas de signos não verbais, ou de um sistema de signos para outro, por exemplo, da literatura para o cinema, a dança, a pintura ou a música.

Sobre o signo, Charles Sanders Peirce, teórico americano, sendo um dos mais importantes pensadores acerca da semiótica, diz que o mesmo não é uma entidade monolítica, mas um complexo de relações triádicas, relações estas que, tendo um poder de autogeração, caracterizam o processo sígnico como continuidade e devir (PLAZA, 1987).

Peirce apresenta suas ideias ligadas ao plano lógico-fenomenológico. Sua teoria semiótica é fonte de estudo para diversos pesquisadores (ECO, 2006; PLAZA, 1987; SANTAELLA, 2005), onde sua doutrina corresponde aos modos como se dão os processos de ação dos signos, ou semiose.

Para o autor, o signo refere-se a:

Qualquer coisa que conduz alguma outra coisa (seu interpretante) a referir-se a um objeto ao qual ela mesma se refere (seu objeto) de modo idêntico, transformando-se o interpretante, por sua vez, em signo, e assim sucessivamente ad infinitum (PEIRCE, 1974, p. 74).

Esta relação tríadica é explicitada em representamen (signo), objeto e interpretante, sendo que o primeiro correlato, o representamen, é considerado como de natureza mais simples e o terceiro, o interpretante, possui natureza mais complexa.

A primeira divisão proporciona dez tricotomias e sessenta e seis classes de signos, a última, três tricotomias e dez classes de signos, porém não vamos nos ater às divisões sígnicas e suas aplicações. 
A primeira relação, conforme o signo em si mesmo for uma mera qualidade, um existente concreto, ou uma lei geral. A segunda, conforme a relação existencial com seu objeto ou em sua relação com um interpretante. A terceira, conforme seu interpretante possui função de um signo de possibilidade ou como um signo de fato ou como um signo de razão (PEIRCE, 1974).

A infinitude da cadeia semiótica é apresentada por Peirce da seguinte forma:

\begin{abstract}
A ideia mais simples de terceiridade dotada de interesse filosófico é a ideia de um signo ou representação. Um signo "representa" algo para a ideia que provoca ou modifica. Ou assim é um veículo que comunica à mente algo do exterior. O "representado" é seu objeto; o comunicado, a significação; a ideia que provoca, o seu interpretante. O objeto da representação é uma representação que a primeira representação representa. Pode conceber-se que uma série sem fim de representações, cada uma delas representando a anterior, encontre um objeto absoluto como limite. A significação de uma representação é outra representação. Consiste, de fato, na representação despida de roupagens irrelevantes; mas nunca se conseguirá despi-la por completo; muda-se apenas de roupa mais diáfana. Lidamos apenas, então, com uma regressão infinita. Finalmente, o interpretante é outra representação a cujas mãos passa o facho da verdade; e como representação também possui interpretante. Aí está nova série infinita! (PEIRCE, 1974, p.99).
\end{abstract}

Segundo Santaella (2007) essa forma de analisar não segue uma receita pronta ou um molde específico; ela apenas atua orientando o processo, uma vez compreendida a heurística da semiose peirceana que privilegia as potencialidades do signo traduzido. Além disso, a autora atesta que o que se analisa é o próprio signo percebido, sem nenhum critério a priori.

$\mathrm{Na}$ história da dança, percebemos inúmeros exemplos de espetáculos criados a partir de obras literárias, movimentos literários e autores. Nos ballets russos de Diaghilev, importante companhia de dança, reconhecida em Paris na primeira metade do século $X X$, vemos dois exemplos: O espectro da rosa (Le spectre de la rose) (1911) realizado pelo coreógrafo Michel Fokine a partir de um poema de Theóphile Gautier; e A tarde de um fauno (L'après-midi d'un faune) (1912), coreografado por Vaslav Nijinsky, é uma transposição do poema homônimo de Stéphane Mallarmé (AGUIAR; QUEIROZ, 2008).

Valeska (2010), que analisa a tradução intersemiótica ocorrida do poema de Stéphane Mallarmé L'après-midi d'un faune para a obra coreográfica homônima do russo Vaslav Nijinsky (1912). Na análise, a potencialidade sígnica é explorada principalmente para a relação de sentidos que a cena poética gera. 
A autora afirma que esse modo de produzir configura-se através de outro gênero que envolve, por si só, um processo tradutório entre os códigos do balé e do filme, concluindo que a dança é uma linguagem mista, devido sua característica híbrida.

É importante citar o trabalho desenvolvido por Daniella de Aguiar (2008), onde criou um modelo sistemático de análise para vídeos de dança. O objetivo foi aplicá-lo aos trabalhos $A$ carne dos vencidos no verbo dos anjos (1998) da Cena 11 Cia. de Dança, que usa como referência a obra do poeta Augusto dos Anjos, e Embodied (2003) do bailarino e coreógrafo Cristian Duarte sobre o livro Philosophy in the Flesh, de Lakoff e Jonhnson (1998).

A autora percebeu, em suas conclusões que as obras representavam novas formas de criar signos para a dança e, portanto, não representavam uma tradução literal das obras de origem, pois elaboravam histórias com características próprias. Isso evidencia uma dimensão "recriativa" específica da tradução intersemiótica para a dança.

A coreógrafa francesa Maguy Marin, apresentou ao mundo em 1981 o espetáculo May B. O trabalho é inspirado na obra dramatúrgica do irlandês Samuel Beckett, não se tratando de uma ou outra obra do dramaturgo, mas de toda a sua proposta poética, de uma forma geral.

Samuel Beckett (1906-1989) é considerado um dos expoentes do teatro do absurdo, o qual se insurgiu contra o realismo psicológico tão característico da burguesia europeia da primeira metade do século XX. Beckett escreve numa época de pós-guerra, havendo na sua obra uma desconfiança irônica com a civilização europeia - criadora de guerras, de carnificinas - esta para ele não tem mais sentido, o mundo se tornou algo inóspito (BRIONES, 2009).

Beckett era conhecido por não ceder facilmente os direitos de autor para diretores montarem suas peças, justificando que não havia alguém que as entendesse. O dramaturgo não só aceitou que Marin montasse um espetáculo de dança a partir de recortes, versões e cortes do conjunto de sua obra, como também quis encontrar pessoalmente com a coreógrafa.

No encontro, Beckett sugeriu a Marin que não respeitasse muito os seus textos, os bailarinos não tinham o porquê de falar trechos das suas obras no palco, porém ela deveria usas as imagens que os textos despertassem nela para criar imagens com o corpo dos bailarinos, assim como também deu outras sugestões para a montagem de May $B$, sendo sempre sugestões cênicas, como as músicas de Schubert, presentes na trilha sonora, foram propostas pelo próprio Samuel Beckett (GREBLER, 2006). 
A poética de Beckett permite a Marin encontrar outros registros de movimentos para a dança: corporeidades incertas, rebeldes, desequilibradas e deselegantes. Como uma das características da obra de Beckett é a imobilidade, característica oposta à dança, Marin seguiu este caminho lhe permitindo focar aspectos impensados até então para sua criação (BRIONES, 2009).

Nas palavras da própria coreógrafa:

No universo de Beckett, a imobilidade é a base. O silêncio também. Tudo começa pela imobilidade e o silêncio. A partir da imobilidade nasce um gesto, e somente um. A partir desse silêncio nasce uma palavra, e somente uma. Um vem após o outro, de modo que o tempo de agir e de falar dure. Para não pensar, para diluir o tempo, para evitar de esperar e de ser na imobilidade e no silêncio (MARIN apud GREBLER, 2006).

May B rompe os moldes da dança francesa sob dois aspectos. O primeiro é o ballet clássico, linguagem artística de forte influência histórica na França, que até a data de estreia de May $B$ tinha impedido o governo a empreender apoio econômico em produções artísticas em dança que não pertencessem a esses padrões clássicos, sendo este o principal público que rejeitou o espetáculo de Marin, por achar que não cumpria com as exigências do belo e harmônico, características pertencentes ao ballet. Por outro lado, houve uma forte influência da dança pós-moderna americana na dança francesa, caracterizada pelos jogos corporais com movimentos abstratos, primando o movimento pelo movimento. May B rompe com os tipos de corporeidades clássicas, aceitas até então como base para bailarinos e propõe uma poética a partir do doente, do emperrado do inábil (MATOS, 2000).

Esta característica estranha, grotesca e fora dos padrões franceses da época, influenciaram a Nova Dança Francesa, movimento análogo à Nouvelle Vague do cinema francês, trazendo grandes contribuições para a história da dança contemporânea.

Segundo Lepecki (2006) a dança é o resultado de uma complexa relação entre diferentes artes e sistemas de linguagem, exibida aos expectadores a linguagem corporal, sendo a princípio a primeira forma de comunicação ao público. Porém existem outros elementos que tradicionalmente já fazem parte do espetáculo de dança, como o cenário, o figurino, a música, além de dispositivos eletrônicos e tecnológicos de interação.

Falando em tradução é importante citar as definições propostas pelo linguista russo Roman Jacobson. Segundo o autor, existem 3 tipos de tradução: a tradução intralingual, a interlingual e a intersemiótica. Assim: 
(...) a poesia, por definição, é intraduzível. Apenas a transposição criativa é possível: ou a transposição intralinguística - tradução de uma forma poética para outra, ou a transposição interlinguística - de uma língua para outra, ou, finalmente, transposição intersemiótica - de um sistema de signos para outro, por exemplo, da arte verbal para a música, dança, cinema ou pintura" (JAKOBSON, 2000, p. 118).

Esta transposição faz parte do dia a dia da dança. Trabalhar com arte é transpor em estética, assuntos, questões, outras obras de outras áreas e, principalmente, criar. A subjetividade do bailarino enquanto criador, tradutor da proposta em dança, em movimento, é um processo de longa duração e eterno, durante todo o trabalho de criação.

Umberto Eco nos fala da importância das relações culturais no processo da tradução:

Entenda que este termo pode parecer obsoleto em face das propostas críticas que, em uma tradução o que conta é o resultado, que se realiza no texto e na língua-alvo. (...) Mas a demonstração de lealdade tem a ver com a convicção de que a tradução seria uma forma de interpretação e a ela deva sempre voltar-se, embora seja partir da conscientização e da cultura do leitor" (ECO, 2006, p. 16).

Assim, fica claro que, para o autor, o processo de tradução está atrelado ao processo de interpretação, afirmando que traduzir é interpretar e não o contrário. O autor propõe três tipos de interpretação: Interpretação por transcrição; interpretação intrasistêmica (correspondendo à intrassemiótica ou intralinguística); e interpretação intersistêmica (relativo à intersemiótica ou interlinguística e transmutação) (ECO, 2006).

Para Haroldo de Campos (1970), toda tradução refere-se a uma "recriação" ou "criação paralela" atinando que, quanto maior a dificuldade de traduzir um signo, mais recriável ele será. Sendo assim, tradução de textos criativos será sempre recriação ou criação paralela, autônoma, porém recíproca. Quanto mais inçado de dificuldades, esse texto será mais recriável, mais sedutor, enquanto possibilidade aberta de recriação.

Júlio Plaza (1987) complementa que toda relação sígnica da tradução intersemiótica existe no tempo: "assim a cadeia semiótica é a cadeia do tempo." Plaza afirma que o passado corresponde à dimensão icônica sígnica da tradução, o presente à dimensão indicial e o "futuro" ao produto final gerado em "busca" da leitura. 
O autor também assume uma relação temporal sígnica, caracterizando o fenômeno como sincrônico e diacrônico. Estabelece uma relação entre as teorizações de Haroldo de Campos, na seguinte passagem:

Em sua transposição literária, o par sincronia/diacronia está em relação dialética em pelo menos dois níveis: a) a operação sincrônica que se realiza contra um pano de fundo diacrônico, isto é, incide sobre os dados levantados pela visada histórica dando-lhes relevo crítico-estético atual; b) a partir de cortes sincrônicos sucessivos é possível fazer-se um traçado diacrônico renovado da herança literária (CAMPOS, 1969, p. 213, apud PLAZA, 1987, p. 03)

O caráter histórico é bastante presente em todo o pensamento do autor. Se pegarmos como exemplo a dança e suas relações com a história, vemos que a mesma interage ativamente com o seu contexto social e período histórico. Outra característica importante da dança é a apropriação de aparatos que a principio não foram criados para uso estético e artístico. O uso do vídeo, na dança, no começo com objetivo de registro coreográfico nos remete à década de 1960.

Steve Paxton, um dos pensadores do método de pesquisa somática em dança, denominado de contato-improvisação, viu na câmera uma possibilidade de registro e análise do que se tem pesquisado. No começo de sua pesquisa, vemos o vídeo apenas como aparato técnico, sem nenhuma pretensão artística e estética.

Com o passar das décadas o nome do bailarino ficou consagrado no meio da dança e sua parceria com o vídeo sempre esteve presente. No começo do século XXI, Paxton tem realizado uma forte pesquisa corporal embasada na coluna e suas características fisiológicas para o movimento e para a dança como meio de conhecimento do próprio corpo.

Material for the Spine, uma grande coletânea de vídeo-aulas, práticas e teóricas, feito a partir de suas pesquisas sobre a coluna, improvisação e exercícios, foi lançado em 2008. O bailarino e pesquisador conseguiu transpor para o vídeo, aquilo que talvez fosse impossível fazer chegar ao público através apenas de palestras, workshops e espetáculos.

Um exemplo desta apropriação é percebido no trabalho de Andrade e Moura (2009), cujo objetivo foi estabelecer uma relação entre corpo, informação e tecnologia. Para isso, as autoras mesclam as instâncias icônica, indicial e simbólica na análise semiótica da tradução que ocorreu no processo de criação coreográfica para o espetáculo Imagens Deslocadas, realizada pelo Movasse Coletivo de Dança de Belo Horizonte. Os corpos dos bailarinos atuavam como 
um suporte que continham as informações, ou signos, responsáveis por mediarem uma instância comunicativa da tecnologia no processo, evidenciada pela crescente aproximação entre os homens e os aparatos em cena (ARAÚJO, 2012).

Spanghero (2003) nos fala que as relações entre tecnologia e dança, podem ser datadas do início da década de 1960, onde os primeiros softwares de notação de movimento começaram a ser criados, potencializando as possibilidades do fazer artístico e dos efeitos da técnica na arte.

Como exemplos deste diálogo entre corpo e imagem, podemos citar os trabalhos do coreógrafo americano Merce Cunningham, responsável por utilizar softwares em espetáculos e pesquisas coreográficas para o vídeo, além das montagens do grupo Cena 11, de Florianópolis, referência nacional e internacional quando o assunto é dança e tecnologia.

O coreógrafo e bailarino Merce Cunningham, interessado no diálogo entre dança e tecnologia, utiliza, a partir daí, softwares e aparelhos em suas criações artísticas. Desta forma, a Merce Cunningham Dance Company, passa a ser referência na dança, criando um novo significado entre corpo e máquina, aliando a estética e a tecnologia em suas obras. Além dos palcos, realizou também vários vídeodanças, um híbrido de coreografias feitas especialmente para o vídeo, com a estética voltada para uma obra em que se percebe o diálogo entre planos de filmagem, coreografias e danças, no sentido mais amplo da palavra.

A Merce Cunningham Dance Company (MCDC) foi criada em 1953, na Black Mountain College e incluiu bailarinos como Carolyn Brown, Viola Farber, Paul Taylor e Remy Charlip e os músicos John Cage e David Tudor. Em 1964, o grupo fazia sua primeira temporada internacional na Europa, vindo a ser uma modificação em sua trajetória, pois abriria as portas para sua repercussão internacional.

McLuhan (1964) nos dizia, já nos anos de 1960, que os meios de comunicação e os instrumentos fabricados pelas novas tecnologias, como a câmera, rádio, TV e vídeo, eram extensões do ser humano. As possibilidades de ver e chegar a lugares antes inalcançáveis é possível graças à tecnologia.

Souza (2001) explana sobre o modo pelo qual o recurso audiovisual possibilita contextualizar e facilitar ao espectador a compreensão dos sentidos coreográficos estabelecidos no jogo intersemiótico. 
Aguiar (2013) nos fala da relação multimidiática da dança, além de suas características interdisciplinares, completando que durante todo o processo de criação em dança, ao longo da história, percebemos suas relações com outros sistemas e meios, como, por exemplo, a música, a literatura, teatro e artes plásticas.

Sabemos que a arte por si só, possui processos comunicacionais, mas que segundo Santaella (2005) as artes estão frequentemente incorporando os dispositivos tecnológicos dos meios de comunicação como processos de sua própria criação artística, assim, ao retratar o processo de criação em dança que envolve diferentes sistemas sígnicos, percebe-se também um caminho para a possível aproximação da dança com outras linguagens.

Neste sentido, é importante a definição de "corpomídia", proposto pelas professoras Christine Greiner e Helena Katz (PUC-SP). O conceito de "mídia" do "corpomídia" é entendido como um processo sempre presente e contínuo de "selecionar informações que passa a fazer parte deste corpo de forma bastante singular, ou seja, são transformadas em corpo" (KATZ; GREINER, 2005). Nesse processo, as informações que correspondem ao motivo das mudanças desse "corpo" não são "processadas", mas coligidas em um fluxo constante, e em via de mão dupla, entre o que vai do exterior ao corpo para o seu interior e vice-versa.

A ideia de "mídia" não emprega a ideia de corpo como suporte ou veículo, ultrapassando a ideia de haver somente uma ligação do que está dentro e fora dele, mas de um corpo que é "mídia". Assim, o corpo não é tomado como um meio em que as informações chegam e são transmitidas, mas de um "todo" (entre o homem e o ambiente) em constante dinamismo coevolutivo, negando também a dicotomia "corpo e mente" (ARAÚJO, 2012).

Segundo Katz (2003), no conceito "corpomídia", a instância comunicativa é estabelecida quando o corpo se movimenta, evidenciando suas relações com o ambiente, ou seja, considerando as interações do corpo com o "outro". Esse "outro", por sua vez, extrapola a dimensão física do humano, possibilitando o diálogo do corpo na forma de um circuito em comunicação com o mundo, traduzindo-o.

$\mathrm{Na}$ dança, teríamos o corpo como meio e a mensagem sendo produzida pelo próprio corpo que dança. Seria uma afirmação do tipo: o corpo é a mídia da dança. E realmente parece ser. A dança é feita pelo corpo, no corpo e para o corpo, e é por meio dele que os discursos 
poético-coreográficos são construídos e emitidos. Na criação da dança há mobilização voltada ao estudo do corpo que dança como principal agente significativo e construtor de sentido no discurso coreográfico (SILVA; GROTTO, 2010).

Podemos dizer que a dança, como um campo artístico, reincorpora elementos não usuais (até então) na criação artística, mudando seu significado e recriando suas possibilidades de coreografar, dançar e utilizar o corpo como essência, que vai dialogar com outros meios em suas obras.

O corpo enquanto principal ferramenta e objeto para a criação em dança possui, em sua essência, características tradutoras, pois sua incorporação aos elementos externos ao corpo e relativos à estética, é imensamente grande. As capacidades de criação e diálogo se tornaram marcas registradas da criação em dança no final do século XX e inicio do século XXI.

Não só a contextualização da intermidialidade se faz justa quando o assunto é criação em dança nos últimos 40 anos, ainda temos a dança como uma ferramenta sígnica: o corpo é capaz de traduzir em movimentos e coreografias aquilo que se propõe, fazendo da dança, neste sentido, um processo intersemiótico.

Artigo recebido em maio de 2015, aprovado em junho de 2015 e publicado em julho de 2015.

\section{Referências}

AGUIAR, Daniella de. Da literatura para a dança: a prosa-poética de Gertrude Stein em tradução intersemiótica. Tese de doutorado. Programa de Pós-Graduação em Letras UERJ. Rio de Janeiro. 2013.

AGUIAR, Daniella de; QUEIROZ, João. (2008). Sobre tradução intersemiótica e aplicações em dança. (monografia apresentada ao edital de apoio à pesquisa da Fundação Cultural do Estado da Bahia).FUNCEB/UFBA, Salvador. 2008. Disponível:<http://www.fundacaocultural.ba.gov.br/institucional/arquivos/danca2008/rf_edac_art-edu07/sobtraduinterdan.pdf>. Acesso em janeiro de 2014.

BRIONES, Hector. Um ruído de asas, de plumas...: reflexões sobre o espetáculo May B, de Maguy Marin. Cadernos do GIPE-CIT: Grupo Interdisciplinar de Pesquisa e Extensão em Contemporaneidade, Imaginário e Teatralidade. Programa de Pós-Graduação em Artes Cênicas da Universidade federal da Bahia, n² 22. 2009.

CAMPOS, Haroldo de. Metalinguagem e outras metas: ensaios de teoria e crítica literária. $2^{\text {a }}$ Ed. Petrópolis: Nosso Tempo. 1970.

CANTON, K. E o príncipe dançou... o conto de fadas da tradição oral à dança contemporânea. Editora Ática, 1994.

ECO, Umberto. Dire quasi la stessa cosa: esperienze di traduzione. $4^{a}$ Ed. Milano: Studi Bompiani. 2006. 
GREBLER, Albertina. Coreografias de Pina Bausch e Maguy Marin: a teatralidade de uma Dança Contemporânea. Tese de Doutorado. Programa de Pós-Graduação em Artes Cênicas. UFBA. Salvador. 2006.

JAKOBSON, Roman. On linguistic aspects of translation. In.: VENUTI, Lawrence (edited). The translation studies reader. London; New York: Routledge. P. 113-118. 2000.

KATZ, Helena; GREINER, Christine. Por uma teoria do corpomidia ou a questão epistemológica do corpo. Cuenca, UCLM: Archivo Virtual de Artes Escénicas.2005. Disponível em <http://artesescenicas.uclm.es/archivos_subidos/textos /237>. Acesso em fevereiro de 2014

LEPECKI, André. Exhausting dance: performance and the politics of the movement. New York: Routledge, 2006.

MATOS, Lúcia. Corpo, identidade e a Dança Contemporânea. Cadernos GIPE-CIT. Salvador, nº 10. 2000.

MCLUHAN, Marshall. Os meios de comunicação como extensão do ser humano. Cultrix. 1964.

PEIRCE, Charles Sanders. Semiótica. São Paulo: Perspectiva. 1974.

PLAZA, Julio. Tradução intersemiótica. São Paulo: Perspectiva. 1987.

SANTAELLA, Lúcia. Matrizes da linguagem e pensamento. São Paulo: lluminuras. 2005. Semiótica aplicada. São Paulo: Thomson. 2007.

SASPORTES, J. Pensar a dança: a reflexão estética de Mallarmé a Cocteau. Editora Imprensa Nacional - Casa da Moeda. 1983.

SILVA, Diego da. GROTTO, Valdair. Vídeo, Dança e Comunicação e suas ligações com mídia. XII Congresso de Ciências da Comunicação na Região Centro-Oeste. Goiânia Intercom Centro-Oeste. 2010.

SOUZA, Aguinaldo Moreira. Body word. language confluence in night journey. Revista Trans-Form-Ação. Marília, vol.24, no 1. 2001. Disponível em: <http://www.scielo.br/scielo.php?script=sci_arttext\&pid=S0101-31732001000100012>Acesso em novembro de 2014. SPANGHERO, Maíra. A dança dos encéfalos acesos. São Paulo: Itaú Cultural. 2003.

VALESKA, Olga. Dança e linguagem: a semiótica como via de acesso. In: IX SEMINÁRIO NACIONAL DE DANÇA CONTEMPORÂNEA DA UFMG, Belo Horizonte. Anais eletrônicos... IX Seminário Nacional de Dança Contemporânea da UFMG. Belo Horizonte: PRODAEXEEFFTO/ UFMG. P. 91- 99. 2010. 